\title{
Bronchial Vegetal Foreign Bodies in the Dog —Localization in 47 Cases
}

\author{
Matteo CERQUETELLA ${ }^{1) *}$, Fulvio LAUS ${ }^{1)}$, Emanuele PAGGI ${ }^{1)}$, Tamara ZUCCARI $^{1)}$, Andrea SPATERNA ${ }^{1)}$ and \\ Beniamino TESEI ${ }^{1)}$ \\ ${ }^{1)}$ School of Veterinary Medical Sciences, University Veterinary Teaching Hospital (UVTH), University of Camerino, Via Circonvallazione \\ 93/95, 62024 Matelica (MC), Italy
}

(Received 9 November 2012/Accepted 2 February 2013/Published online in J-STAGE 15 February 2013)

ABSTRACT. In the present work, a retrospective study on the localization of vegetal foreign bodies (VFBs) inside the tracheobronchial tree of 41 dogs is reported. In total, 47 grass awns were found, and only three dogs presented more than one foreign body. Most VFBs were found inside right bronchial ramifications (76.6\%, no. 36), while $23.4 \%$ (no. 11) were found inside the ventrocaudal branch of the left cranial lobar bronchus. The impossibility of predicting the location and the concomitant presence of more than one foreign body in a single patient are conditions that impose the need for careful evaluation of the whole bronchial tree in all cases.

KEY WORDS: bronchoscopy, canine, foreign body, foxtail, grass awn.

doi: 10.1292/jvms.12-0494; J. Vet. Med. Sci. 75(7): 959-962, 2013

Many cases of inhaled/aspired vegetal foreign bodies (VFBs) have been reported in the literature in dogs $[2,4,5$, $8,10,11]$. The most frequent ones are awns provided grass inflorescences (foxtails) $[10,11]$. Once inhaled, these foreign bodies (FBs) tend to deepen their position also migrating trough the pulmonary parenchyma to other body districts $[7,11]$. Ultrasonography, radiology, computed tomography and magnetic resonance imaging have been tested in order to diagnose the presence of FBs [1, 3, 11, 12], but with regard to bronchial FBs, endoscopy still represents the most interesting one, allowing both diagnosis and, frequently, direct removal. Even though many cases of bronchial VFBs have been described in the literature, most articles have described single cases, while to the authors' knowledge, only a few studies with a large number of dogs have described the localization of FBs along the bronchial tree $[2,10,11]$. The aim of the present study was to provide further data about the "preferential" localization of VFBs along the lobar and segmental bronchial ramifications of dogs after their aspiration.

Forty-one dogs subjected to bronchoscopy at the University Veterinary Teaching Hospital (UVTH), Camerino University, because of the presence of respiratory difficulties were found to have VFBs in the branching of their lower airways. For all dogs, the clinical history was similar, and each was referred for a cough that started suddenly while the dog was engaged in activities outdoors, which then lasted for different periods of time (from 2 to 4-5 months). Also, clinical signs were similar in all patients and were characterized by cough, productive or not, and sometimes crackles and wheezes. Dogs in which FBs were present for two

\footnotetext{
*Correspondence to: Cerquetella M., School of Veterinary Medical Sciences, University Veterinary Teaching Hospital (UVTH), University of Camerino, Via Circonvallazione 93/95, 62024 Matelica (MC), Italy.

e-mail: matteo.cerquetella@unicam.it

(C)2013 The Japanese Society of Veterinary Science
}

months or more also presented exercise intolerance and poor athletic performances. The most relevant laboratory finding was mild neutrophilia in chronic cases. Of the patients, 37 were hunting dogs, 24 were male and 17 were female (Table 1). The ages of the dogs ranged between 1 and 9 years. Almost all cases were presented from February to September, with only four in October (patients 3, 15, 16 and 41) and only one in January (patient 24). To perform the endoscopic evaluation, two different instruments, each provided of alligator jaws grasping forceps were used; one was a fiberscope (VFS-2A, VetVu ${ }^{\circledR}$, Oxford, MA, U.S.A.; 6.0 mm external diameter and $100 \mathrm{~cm}$ length), while the other one was a video endoscope (Mercury Endoscopia Italiana, Foligno, Italy; 4.2 $\mathrm{mm}$ external diameter and $90 \mathrm{~cm}$ length). In total, $47 \mathrm{VFBs}$ (all grass awns) were found (Table 1). The bronchial mucosa endoscopic appearance was different depending on the time of FB persistence; in cases in which the FB was removed soon after its aspiration, the mucosa was variably erythematous, but usually in the absence of mucus. In more chronic cases, the mucosa was variably hyperemic and had an irregular surface, and there was often mucus that partially hid (completely in one case, no. 22) the FB. After FB endoscopic removal, some patients (those with the worst endoscopic appearance or with mucus) were treated with antibiotics for different periods of time; for patients $3,15,16,24$ and 41 (the most chronic ones), the antibiotic was chosen based on bacteriological examination and correlated antibiotic assay results. In cases in which the mucosa appeared particularly inflamed, an anti-inflammatory drug was also associated. In patient 22 (grass awn in the right caudal lobar bronchus), it was impossible to remove the FB endoscopically, as it was hidden by mucus and firmly trapped in depth, and thus, it was removed surgically.

Most inhaled vegetal foreign bodies can persist inside nasal cavities, can be swallowed or can pass trough the trachea to bronchial ramifications. The vast majority, 37 out of 41 , of the dogs reported in the present study were hunting dogs; this is likely due to outdoor activities that 
Table 1. Breed, sex distribution, localization and absolute and percentage distributions of FBs inside the bronchial tree of patients included in the study

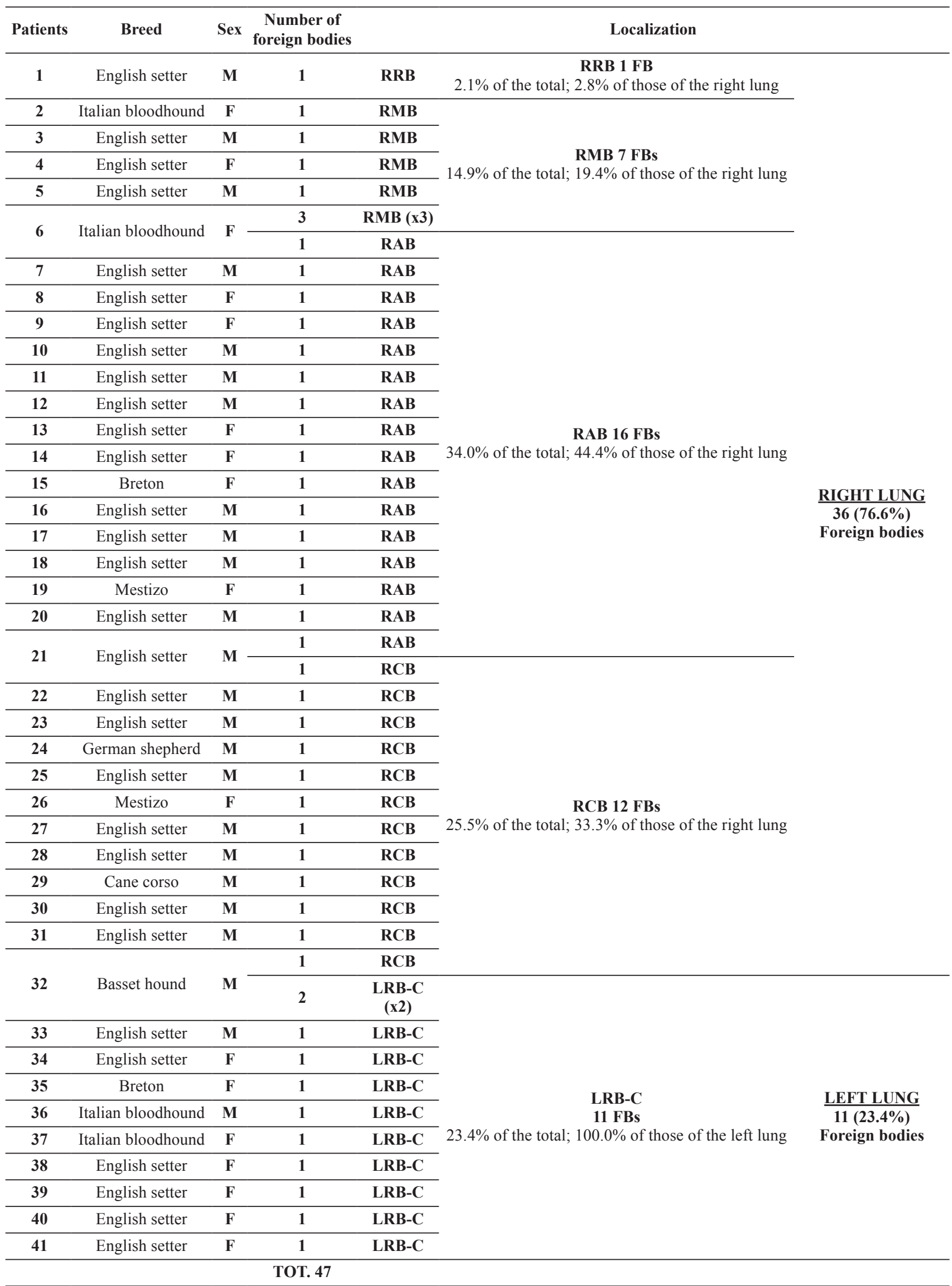

$\underline{\mathrm{LRB}-\mathrm{C}}$, ventrocaudal branch of the left cranial lobar bronchus (left cranial lung lobe); $\underline{\mathrm{RRB}}$, right cranial lobar bronchus (right cranial lung lobe); $\underline{\mathrm{RMB}}$, right middle lobar bronchus (right middle lung lobe); $\underline{\mathrm{RAB}}$, right accessory lobar bronchus (right accessory lung lobe); $\underline{\mathrm{RCB}}$, right caudal lobar bronchus (right caudal lung lobe). 
these dogs were usually involved in, often in environments in which VFBs are normally present. Likewise, foxtails inhalation/aspiration seems to show a seasonal incidence (mainly spring and summer), being elevated the time spent outdoors in such periods; also, in those dogs in which FBs were diagnosed in different periods, it was likely that the FBs were almost certainly present from that time (spring and summer) according to the owners' anamnestic reports. VFBs were mostly localized inside the right lung (Table 1) in our cases, as has been reported in other studies $[2,5,8,10$, $11]$; the more straight angle that is usually seen between the right principal bronchus/carina than left principal bronchus/ carina [6] may contribute to the prevalent distribution to the right lung. More precisely, $76.6 \%$ of FBs were found inside the segmental branches of the right main bronchus, and $23.4 \%$ were found inside the segmental branches of the left main bronchus. Interestingly, all FBs found inside the left lung were localized inside the first lobar ramification (left cranial lobar bronchus - LRB) and precisely at the level of its ventrocaudal segmental branch (caudal section of the left cranial lung lobe - LRB-C); no FBs were positioned inside the ventrocranial segmental branch (LRB-R) (cranial section of the left cranial lung lobe) or inside the left caudal lobar bronchus (LCB) (left caudal lung lobe). The authors suppose that this could be partly due to the openings of the LRB and LCB, which usually represent a sort of bifurcation of the left main bronchus, with the LRB more cranial and ventral. The distribution of FBs inside the right lung could appear strange, with the majority located inside caudal ramifications, and it would indeed be logical to expect a higher presence inside the first branches, which are the ventrolateral (right cranial lobar bronchus, RRB) and ventral branches (right middle lobar bronchus, RMB); this could be justified by the angle of attachment of such lobar branches, because the right accessory lobar bronchus (RAB) and right caudal lobar bronchus (RCB) appear to be, in some cases, more parallel to the right main bronchus, while the RRB and RMB could be attached more perpendicularly to the right main bronchus. Comparing our results with those of a previous study [9] performed on dogs with aspiration pneumonia, it is interesting to notice that in dogs with aspiration pneumonia, the right lung was most affected compared with the left lung, as happened in our cases, but differently, with regard to the right side, the most affected lobes were the right cranial and middle ones, which in the present study were less affected than the RAB and RCB. Similarly, in a study of Tart et al. [13] also performed on dogs affected by aspiration pneumonia, the middle and cranial right lung lobes were more affected than the right caudal lobe. It is difficult to make a comparative evaluation with regard to the left lung because the FBs in our cases were only located inside the LRB-C. It is possible that the different composition and dimensions of materials inspired could justify their different locations inside the right lung in the two studies performed on dogs with aspiration pneumonia compared with the dogs of the present study. Another peculiar datum, however, needing further confirmation is apparent if the patients are divided into males and females, because it is possible to see that in females, there is a higher frequency of VFBs located inside the left lung (17 females, 7 left and 13 right; 24 males, 3 left and 24 right). We found more than one FB in three out of 41 patients, suggesting that the retrieval of multiple VFBs in a single patient could be considered a rather infrequent event; however, this aspect must not in any case cause the operator to neglect careful and complete visualization of the whole bronchial tree. The presence of mucus inside a single lobar or segmental branch is an important sign suggesting the presence of a FB, but lack of it is not indicative of FB absence. Finally, in our cases, endoscopy was always able to diagnose FB presence, and only in one case (patient 22) was it impossible to remove the grass awn, because of its deep position. In any case, endoscopy was also fundamental in this case, because it allowed execution of an aimed surgery by exactly locating the FB's position.

In conclusion, in our patients, VFBs were located mainly inside right bronchial branches, especially the two distal ones; nevertheless, the impossibility of predicting the location and the concomitant presence of more than one FB in a single patient are conditions that impose the need for careful evaluation of the whole bronchial tree in all cases, paying particular attention to those situations in which the lumina of the deepest branches are not visible because of the presence of mucus, because this condition could hide a FB.

\section{REFERENCES}

1. Armbrust, L. J., Biller, D. S., Radlinsky, M. A. G. and Hoskinson, J. J. 2003. Ultrasonographic diagnosis of foreign bodies associated with chronic draining tracts and abscesses in dogs. Vet. Radiol. Ultrasound 44: 66-70. [Medline] [CrossRef]

2. Brownlie, S. E. 1990. A retrospective study of diagnosis in 109 cases of canine lower respiratory disease. J. Small Anim. Pract. 31: 371-376. [CrossRef]

3. Caywood, D. D., Kramek, B. A., Feeney, D. A. and Johnston, D. R. 1985. Hypertrophic osteopathy associated with a bronchial foreign body and lobar pneumonia in a dog. J. Am. Vet. Med. Assoc. 186: 698-700. [Medline]

4. de Brito Galvao, J. F., Ball, R., Kidder, A., Baan, M., Birchard, S. J. and Drost, W. T. 2012. What is your diagnosis? J. Am. Vet. Med. Assoc. 240: 37-38. [Medline] [CrossRef]

5. Dobbie, G. R., Darke, P. G. G. and Head, K. W. 1986. Intrabronchial foreign bodies in dogs. J. Small Anim. Pract. 27: 227-238. [CrossRef]

6. Eom, K., Seong, Y., Park, H., Choe, N., Park, J. and Jang, K. 2006. Radiographic and computed tomographic evaluation of experimentally induced lung aspiration sites in dogs. J. Vet. Sci. 7: 397-399. [Medline] [CrossRef]

7. Hopper, B. J., Lester, N. V., Irwin, P. J., Eger, C. E. and Richardson, J. L. 2004. Imaging diagnosis: pneuomothorax and focal peritonitis in a dog due to migration of an inhaled grass awn. Vet. Radiol. Ultrasound 45: 136-138. [Medline] [CrossRef]

8. Jones, B. D. and Roudebush, P. 1982. The use of Fiberoptic Endoscopy in the Diagnosis and Treatment of Tracheobronchial Foreign Bodies. J. Am. Anim. Hosp. Assoc. 20: 497-504.

9. Kogan, D. A., Johnson, L. R., Jandrey, K. E. and Pollard, R. E. 2008. Clinical, clinicopathologic, and radiographic findings in dogs with aspiration pneumonia: 88 cases (2004-2006). J. Am. Vet. Med. Assoc. 233: 1742-1747. [Medline] [CrossRef]

10. Lotti, U. and Niebauer, G. W. 1992. Tracheobronchial Foreign 
Bodies of plant origin in 153 Hunting Dogs. The Compendium - Small Animal 14: 900-904.

11. Schultz, R. M. and Zwingenberger, A. 2008. Radiographic, computed tomographic, and ultrasonographic findings with migrating intrathoracic grass awns in dogs and cats. Vet. Radiol. Ultrasound 49: 249-255. [Medline] [CrossRef]

12. Staudte, K. L., Hopper, B. J., Gibson, N. R. and Read, R. A. 2004. Use of ultrasonography to facilitate surgical removal of non-enteric foreign bodies in 17 dogs. J. Small Anim. Pract. 45 395-400. [Medline] [CrossRef]

13. Tart, K. M., Babski, D. M. and Lee, J. A. 2010. Potential risks, prognostic indicators, and diagnostic and treatment modalities affecting survival in dogs with presumptive aspiration pneumonia: 125 cases (2005-2008). J. Vet. Emerg. Crit. Care (San Antonio) 20: 319-329. [Medline] [CrossRef] 